\title{
Sixth former takes oral health to primary school children
}

M y name is Neha Kanda and I am a sixth form student at Wolverhampton Girls' High School applying for dentistry this October.

While on work experience at various dental practices, the vast disparities in the level of oral health and dental hygiene in children, based upon the socio-economic status of the area, struck me greatly. I spent two weeks at two mixed practices and two weeks at two NHS practices.

With Wolverhampton being within the top 20 most deprived areas in the UK, I initiated a project, following my work experience, to perform a workshop at a local primary school in an area with a particularly low socio-economic status, educating the children about preventative dentistry and maintaining a good standard of dental health in an interactive, informative and memorable way.

The workshop was carried out at Merridale Primary School Wolverhampton with year 2 children, aged 6-7. I was accompanied by my fellow pupil, Saairah Anwar, who hopes to study medicine.

Incorporating the tips and advice given to me by Dr Jonathan Lewney, Associate

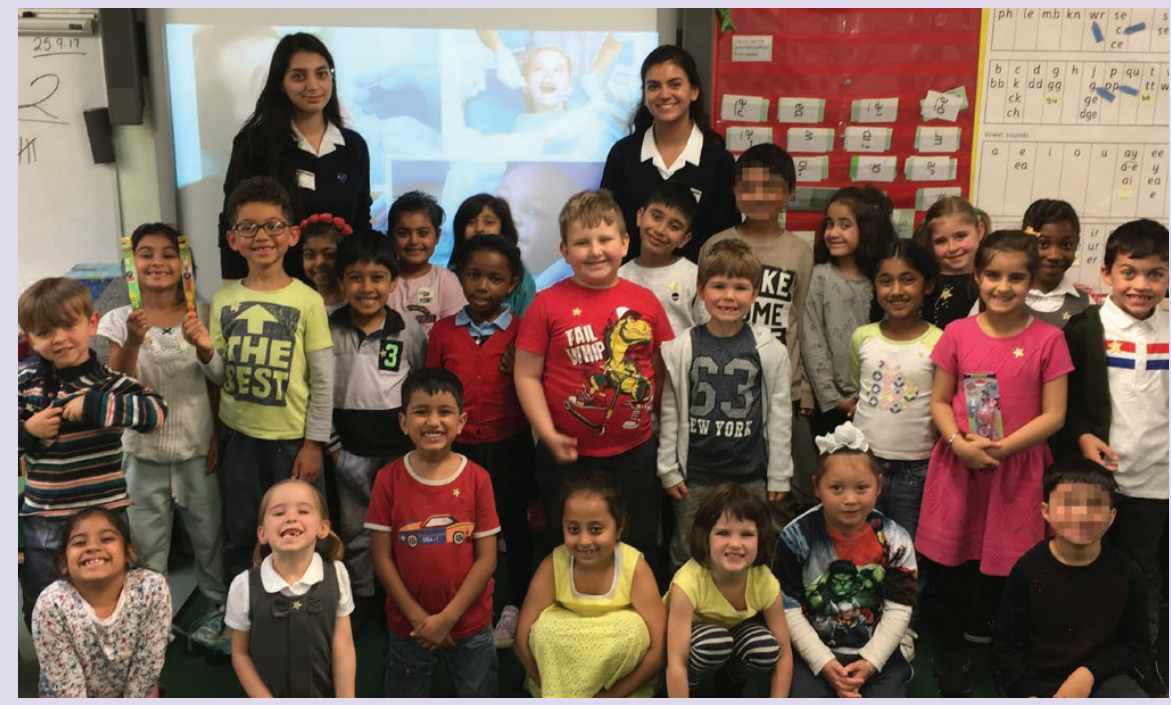

Sixth formers Neha Kanda and Saairah Anwar teach local primary school children about looking after their teeth

Editor $B D J$ Portfolio, I put together and gave the presentation on 25 September, and was commended for carrying out an 'engaging, thoughtful and informative' session.

Ranging from the importance of teeth and a healthy diet, to brushing techniques, fluoride toothpaste and even dental caries, the children interacted well and were eager to learn new information throughout. It was very fulfilling finishing the session knowing that the children had taken something away from the afternoon and were genuinely enthusiastic to put into practice what they had been taught. Beginning the session with the children not even knowing the basics of good oral hygiene, to finishing with a quiz where all 25 children were buzzing with excitement to tell me the correct answer, was one of the most satisfying aspects of the day.

\section{BASCD conference to focus on working with communities}

A key aim of the British Association for the Study of Community Dentistry (BASCD's) Autumn scientific conference is the benefits and challenges of working with communities to improve oral health.

Inequalities in oral health is a repeated concern in many parts of the country. A lot of emphasis has been given to strategies which focus on improving the behaviour of individual patients, and increasingly on large scale media campaigns, policy actions etc as ways to tackle the problem.

The conference will take place on 16 November 2017 at the Cavendish conference centre in London. Sir Harry Burns, a former Chief Medical Officer for Scotland until 2014 and now Professor of Global Public Health at Strathclyde University, will be the keynote speaker. He draws on his clinical experience working with patients in the east end of Glasgow to give an insight into the complex inter-relationships between social and economic status and illness, and has been particularly prominent in advocating for 'co-producing' health and using assets which are present, even in deprived areas.

This will be followed by a presentation by Professor Lorna Macpherson from the University of Glasgow who will outline what we know about community-level approaches to tackling oral health inequalities. There will then be an example of a community-based programme where an oral health component is embedded within a wider initiative targeting young families, and which uses a model of community volunteers as mentors.

For more information and to register, visit http://www.bascd.org/.

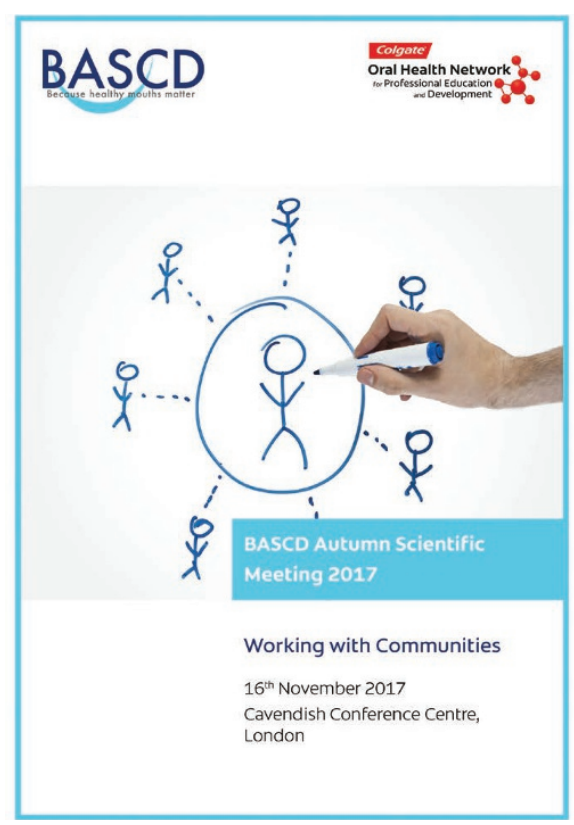

